\title{
Fewer Canadian MDs heading to the US
}

Cite as: CMAJ 2017 July 4;189:E898. doi: 10.1503/cmaj.1095419

$\mathrm{T}$ he physician brain drain that began in the 1990s - when it was estimated that the equivalent of two graduating classes left each year to practise in the United States - is definitively over.

"We are now graduating more physicians than ever before ... and fewer are leaving for the US," says Dr. Thomas Freeman, principal investigator of a recent study documenting a major decline in the number of Canadian physicians leaving to work below the 49th parallel. The researchers examined the American Medical Association (AMA) masterfile to identify graduates of Canadian schools of medicine working in the US in direct patient care.

From 1970 to 1990 , approximately 200 Canadian medical school graduates (CMGs) headed south to practice every year. That number rose sharply between 1990 and 1995, in some years exceeding 250 graduates. Then there was an abrupt decline. By 2000, the number of CMGs in the US was lower than at any time since the 1970 s.

That rate has continued to decline, notes Freeman, who is also a professor at the Schulich School of Medicine and Dentistry in London, Ont. "We found that the number of CMGs practicing in the US fell from 8162 in 2006 to 6709 in 2015."

The study, "Shifting tides in the emigration patterns of Canadian physicians to the United States: a cross-sectional secondary data analysis," published online by BMC Health Services Research, found that only 27 CMGs who graduated between 2009 and 2011 appear in the 2015 AMA Physician Masterfile.

According to the Canadian Medical Association's Canadian Collaborative Centre for Physician Resources, the original exodus of doctors came as a result of signals from government "that doctors were

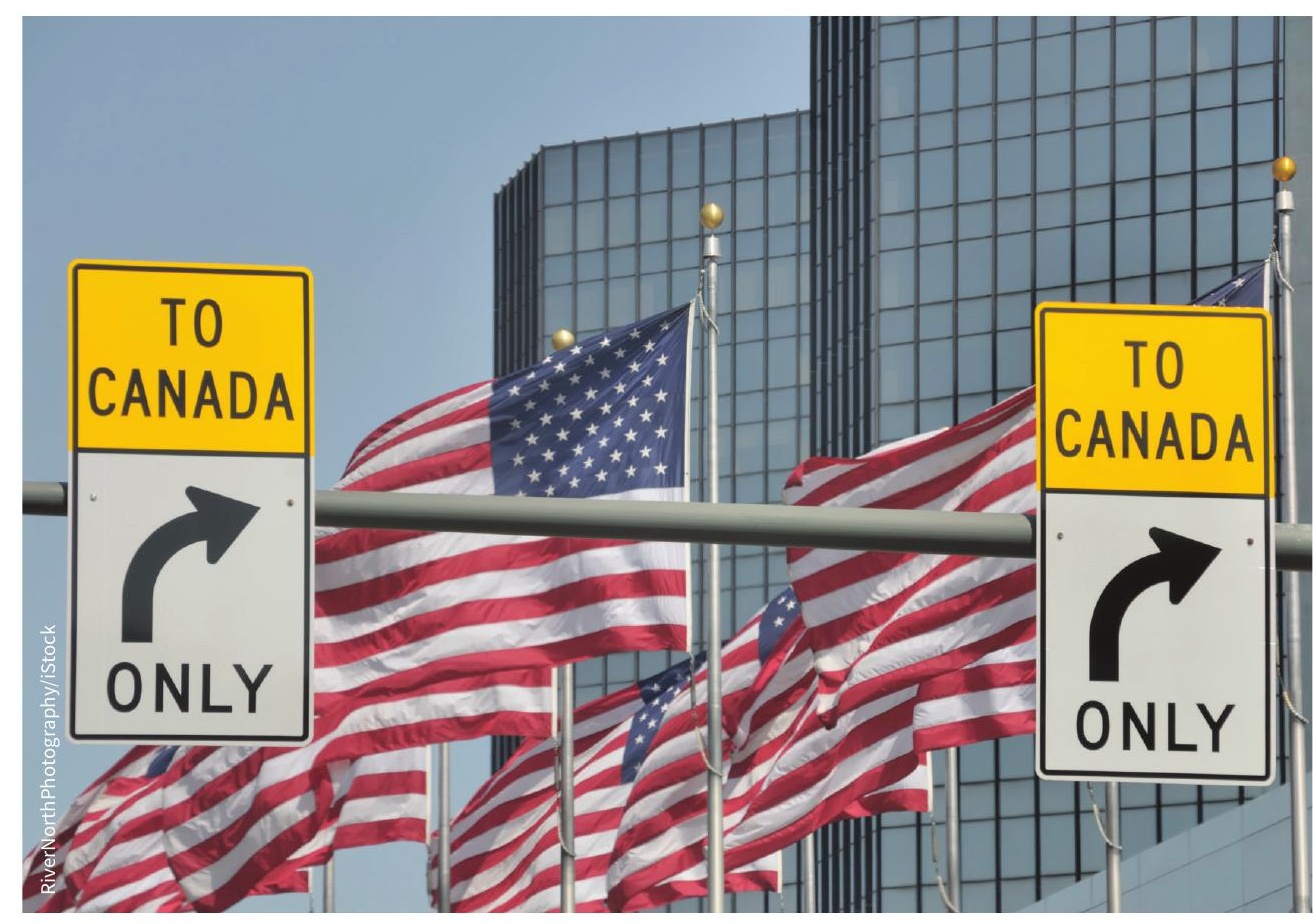

The exodus of Canadian MDs to the US appears to have ended.

not welcome in Canada." This message was mirrored in cuts to medical school enrollment and reduced opportunities for international medical graduates (IMGs). However, by the mid-1990s, Canada was experiencing a shortage of doctors and medical school enrollment was increased while restrictions on IMGs were eased.

Increased funding was also targeted at reducing waiting times, which created greater opportunities for physicians, notes Freeman. As well, physicians were allowed to form private professional corporations which help to alleviate income differentials with US counterparts.

At present, there are some job shortages in the surgical field, but most physicians are able to find work in Canada, according to the Canadian Medical Association (CMA). This makes a move to
America less attractive, a message the US has appeared to receive. "There is not as yet a lot of evidence that US recruiters are up here looking for physicians the way they were back in the 1990s and early 2000s," notes the CMA.

However, employment-related factors change frequently, says Freeman, who recommends a national health human resource plan be put in place "if we are to avoid the perceived shortages and surpluses that have been seen in the past few decades."

The CMA endorses the need for a national planning tool. "Canada's physicians are highly mobile - you cannot plan for a single region effectively when there is so much mobility."

donalee Moulton, Halifax, NS 